\title{
A LUTA PELA JUSTIÇA SOCIAL NO ROMANCE HISPANO - AMERICANO
}

\author{
Temístocles Linhares*
}

em fugir a nenhum dos problemas que afligem o homem, o romance hispano-americano mantém intacto o prestígio dos fatores sociais. Crê na justiça que os encarna, ainda quando ela esteja longe de se corporificar na ação e se esconda sob a forma de longínqua meta a atingir.

Dentro de semelhante postura, uma vez que ao romance não cabe fazer proselitismo ou defender ideologias, é que podemos situar ou antes delimitar a complexidade de Ciro Alegria, romancista peruano, que se desenvolve exclusivamente no âmbito rural, na zona do campo, cenário natural de seus três romances: La serpiente de oro, Los perros hambrientos e El mundo es ancho y ajeno.

Tendo vivido na província de Huamachuco, numa fazenda de seu avô paterno, o autor entrou na intimidade dos peões e dos lavradores. Ali conheceu as terras e homens que povoariam seus romances.

Assim, La serpiente de oro, denominação dada ao rio Marañón, está referto de reminiscências da sua i nfầncia, transcorrida às margens desse rio $\mathrm{e}$ das selvas dominantes na região Norte do Peru, de que o livro chega a ser uma espécie de canto ou pastoral. A decoração está disposta em função não só dos

* Universidade Federal do Paraná 
elementos naturais, personagens vivas e atuantes, como também das intençōes históricas, políticas e sobretudo sociais. Não há propriamente ação no livro e o que impressiona mais o autor, de par com a natureza, é a existência miserável do índio. Assim, o que avulta nele é a sua força descritiva, fazendo a vida em torno encontrar reflexo na selva e no rio.

Já em Los perros hambrientos a facilidade narrativa alcança nota mais alta. É bem da difícil facilidade que se trata, conseguida à custa de muito esforço e especialmente da vontade de ser sincero, como notou Luis Alberto Sánchez, que lhe permite aproximar-se de Thomas Mann, um John dos Passos, ou um Jack London, aliás influências bem visíveis nesse livro como no que vem depois.

O segundo romance de Alegria, porém, talvez seja o mais original de seus livros. Os cães, é certo, já figuraram em muitos livros de Jack London e Rudyard Kipling como em outros autores. Mas os que surgem em Los perros hambrientos se distinguem dos outros, nem se inspiram neles. Talvez sejam menos letrados que os de Cervantes até. São, contudo, autênticos cidadãos da Perrolândia andina, como diz o mesmo Sánchez, pois transudam fome, rancor, - abatimento e raiva, a ponto de se desvanecerem diante de suas presenças os perfis de bandoleiros e índios traçados no livro. Há até a possibilidade de classificá-lo em duas categorias: na primeira, as façanhas e paixões de Güeso, Wambra e Pellejo; na segunda, as de Zambo, Rafles e Shagra. A história de Güeso, raptado pelo bandido Celedón, já foi apontada como das melhores que se conhecem sobre a espécie. O animal doméstico se converte em cão de facínora, apresentando assim um tipo de instrospecção canina fora do comum.

Com absoluto domínio literário, o autor ainda lembra as voltas de seu destino, sem esconder preocupações sociais diante de vários problemas, muitos deles criados pelo proprietário crioulo, abusivo e prepotente. Sem precisar recorrer à imaginaçāo ele vai retratando os seus tipos, índios e mestiços da preferência, com a ajuda apenas de sua memória e suas recordações.

Em seu terceiro romance, El mundo es ancho y ajeno, talvez o mais afamado dos três, aparecem duas figuras admiráveis, como seres vivos, que são o índio Rosendo Maqui e o feroz Vazquez, bandoleiro que comete barbaridades, mas se impõe pelos seus traços inconfundíveis.

Esses dois heróis gozam realmente de existência própria, fora dos possíveis caprichos do autor ou de seus erros de juízo, fugindo à condição de autômatos inertes e insensíveis. São, portanto, criaturas que vivem por si sós, sem conter nada do que pudesse constituir um mecanismo montado.

De modo geral, os livros de Ciro Alegria, se inscrevem entre os que refletem a realidade agrária do Peru. É esta sem dúvida que lhes imprime caráter especial, parecendo o autor empenhado em retratar todo um vasto capítulo da 
história peruana ligada ao problema da terra. Não significa isso que lhe caibam intuitos moralistas ou propósitos de proteger a sociedade ameaçada com a existência em seu seio de tais seres que pendem mais para o mal, como joguetes das circunstâncias. Seria injusto não reconhecer que diversos elementos históricos estão ligados a muitas de suas páginas, na parte relativa, por exemplo, a inúmeros episódios da Guerra do Pacífico, da Revolução antimilitarista de 1895, etc. Tenazes e vivas recordaçöes do próprio autor, ao lado do jogo das forças ecônomicas, da ação da consciência coletiva, tudo é descrito com segurança e simplicidade, para o que ainda haveria de se acrescentar a inspiração do poeta, através de muitas imagens e intuições que avivam e enriquecem os amplos quadros de uma época e situação verdadeiramente autênticas.

Nesse sentido talvez avulte ainda mais a figura de outro romancista, de papel tão decisivo no romance regionalista da Venezuela, Romulo Gallegos, que se celebrizou com a publicação de Doña Barbara, não obstante outras obras não desmereçam o seu valor diante desse livro.

Não resta dúvida que a importância da natureza, quer como cenário, quer como protagonista, nunca será exagerada no estudo desse romancista. O aspecto social, denunciado tão manifestamente em várias passagens de rebeldia e inconformismo, também é outra característica imprescindível para a sua compreensão.

Além disso, há ainda a considerar o valor literário de obras como Dor̃a Barbara, Canaíma e Cantaclaro, três romances soberbos, suscetíveis de serem analisados do ponto de vista do estilo e da construção romanesca.

Aliás, o primeiro romance de Gallegos não foi nenhum desses, mas Reynaldo Solar, que já tinha o mérito de apresentar personagens identificadas com a terra e o cenário. É esse livro uma espécie de roteiro ou preparação para a leitura dos outros. É a história da dinastia dos Solar, de que fora Hermenegildo, avô de Reynaldo, o "último" representante, mas para cuja reconstituição era preciso definir outros caracteres e figuras conjuntamente com o ambiente, justamente o de onde o autor provinha.

Doña Barbara é o terceiro romance de Gallegos e foi ele que o consagrou como dos maiores romancistas do continente.

O lado humano não pode nele ser separado do lado físico, do seu bárbaro cenário, em que os homens se devoram entre si, seguindo a lei do mais forte.

Doña Barbara encarna assim a violência, descrita sem arroubos de linguagem, na forma mais condizente com a feição do romance, que se desenvolve aos poucos, mas sempre in crescendo, para adquirir volume e penetração à medida que caminha para o seu climax.

Em relação a este livro não se pode dizer que o romance seja apenas veículo do homem, não obstante ele contenha muitos problemas humanos. Nele 
se concentram as faculdades intuitivas do autor que não pode ficar indiferente diante da natureza, de sua influência e simbologia, vendo com ternura uma noite de lua cheia como a descrita nas primeiras cem páginas, quando, sob os tetos das habitações ou sobre as cercas dos currais, havia sempre algum vaqueiro para falar das aparições que vira:

\begin{abstract}
"A ambígua claridade da lua, transtornando as perspectivas, povoa de duendes a campina. São as noites das coisas pequenas que, de longe, se tomam enormes, das distâncias incalculáveis, das formas disparatadas. Das sombras brancas postadas ao pé das árvores, dos cavalos misteriosos, imóveis nos claros das matas, que desaparecem de repente, quando alguém se põe a olhá-los. Noites para viajar, "com calafrios no corpo e a Magnífica nos lábios"- como dizia Pajarote. Noites alucinantes em que até as bestas dormem inquietas..."
\end{abstract}

São ainda os grandes rios e as imensas campinas, a vida forte que eles e elas inspiram e por onde o homem segue sempre cantando o perigo: "É a própria epopéia. $\mathrm{O}$ campo bárbaro sob seu aspecto mais impotente: o inverno que exige mais paciência e mais audácia, a inundação que centuplica os riscos e faz sentir nos pedaços de terra enxuta a enormidade do deserto", embora a grandeza do homem resolva afrontar tudo.

$\mathrm{E}$ as chuvas, as ventanias. A respeito das primeiras, notam-se observações como esta:

"Faz dias que não acontece outra coisa. Os camponeses que estavam fora de suas casas haviam regressado, porque os rios $\mathrm{e}$ riachos transbordaram pelas campinas e breve não haverá caminhos transitáveis, nem meios de percorre-los! Já é tempo de 'fumo, mulher e rede' e com essas três coisas, sob o teto de palha, o camponês se sente feliz, enquanto lá fora as nuvens vão se desfazendo numa chuva copiosa e obstinada."

E as segundas quantas vezes não levavam todas as esperanças, como se vê no capítulo II da $3^{\circ}$ parte!

Forças elementares poderosas assim vão surgindo acompanhadas de presságios e de sonhos, para unir o tempo vital com o tempo existencial, mais veloz, cheio de recordações, capaz de fundir num segundo as experiências 
anteriores, como sucedeu depois que Santos Luzardo regressou da cidade, para pôr em prática os seus projetos de reforma da planície, sem poder nunca fazê-lo. Não foi ele acaso o primeiro a esquecer desses projetos e compartilhar com os peões dos perigos em que viviam, a morte sempre a espreitá-los à beira dos caminhos? Na verdade, a ele também a planície se afiguravam mais bela assim, rude e bravia. "Era a bárbarie; mas se para acabar com esta, não bastava a vida de um homem, para que gastar a sua, combatendo-a"'- ele se interrogava. "Depois de tudo - dizia consigo mesmo - esta vida tem seus encantos, sendo alguma coisa de agradável que vale a pena viver: é a plenitude do homem revoltado contra todas as limitações."

O que ressalta sempre é a postura da terra indômita, em contraste com a sua beleza e a própria opinião de Pajarote, autêntico homem do campo, quando dizia não conceber a existência de nenhum cristão na cidade ou em casas cheias de paredes uma vez que o campo era a terra de Deus para o homem do diabo. Às vezes também este campo, porém, se tomava um demônio e isso se dava quando a lei, encarnada no bacharel Luzardo, pretendia impor as suas normas à adulta e angulosa força primitiva da natureza, muito mais bem representada por Doña Barbara, no seu ódio ao homem, na sua mistura do agradável com o atroz, na sua solidão embrutecedora, "pântano onde havia desaparecido aquele que fora o orgulho dos Barqueros", de que descendia esse mulambo de gente que aparece no livro com o nome de Lorenzo, e em que Santos Luzardo também começava a afundar-se, ainda que sob outro aspecto: o da selvageria, que não perdoa aos que se lançam nela. Na verdade, Luzardo figura principal do livro, já era vítima da natureza ou dessa Doña Barbara, devoradora de homens.

Lorenzo estava realmente no fim. Agora chegara a sua vez:

- "Santos Luzardo! Mira-te em mim! Esta terra não perdoa!"

Era o que justamente Luzardo se dizia a si mesmo, contemplando o rosto pálido do outro, coberto pela cor tenebrosa da morte ao suplantar imaginativamente as feiçōes de Lorenzo pelas suas: - "Logo começaria a embriagar-me para esquecer e ficarei assim, com a feia morte pintada no rosto: a morte do espectro de um homem , a morte de um cadáver."

Não se esqueça que Doña Barbara era uma virago cercada e servida por criminosos, empenhada em aumentar suas terras e rezes por processos fraudulentos. Na planície do alto Orinoco, onde fazia e desfazia, vingava-se da desgraça de que fôra vítima na adolescência, em um acampamento, no qual ela era a única mulher. Três homens sofreram então a sua perturbadora beleza de 
mestiça. Houve verdadeira rebelião provocada pelos seus encantos que acabou culminando no festim de sua virgindade. Daí por diante ela só abrigou rancores no coração e nada lhe agradava mais do que ver um homem debater-se nas garras das forças destruidoras geradas pela tenebrosa ciência dos bruxos e feiticeiros, em que se iniciara. Assim, não era só a sua beleza que perturbava a paz da comunidade, mas também esse poder diabólico haurido da divindade das selvas oriquenhas, misturado às terriveis virtudes das ervas e raízes com que as índias preparavam a "pusana"e de que ela se utilizava para aumentar a luxúria e aniquilar os homens presos às suas carícias. Se a uns o domínio era exercido por essa forma, a outros mandava simplesmente assassinar, sempre em luta com os vizinhos, obtendo da falta de honestidade dos juizes o que a justiça não podia dar-lhe, a ponto de se tornar dona de todo o Capon de Arauca, vasta gleba de terras altamirenhas, incorporada às suas.

Contra ela, pois, é que se propunha lutar Santos Luzardo, após ter terminado o seu curso de direito, depois de ter resolvido administrar a estância abandonada pelos pais, também alvo das depredações habituais de Doña Barbara.

Logo Luzardo verificou que a justiça não resolvia as suas dificuldades e que o único remédio, a única lei dominante na "Llanura"era a violência.

A princípio Doña Barbara viu nele presa fácil, mas tal não aconteceu. Luzardo se interessou mais por Marisela, filha repudiada da "devoradora de homens". Esta não lhe suscitou senão desprezo e indiferença e o resultado foi o inverso. Quem ficou apaixonada foi a própria Doña Barbara, que pensou até em eliminar Marisela, sua rival no amor. Mas isso não chega a se dar, Doña Barbara ela mesma persuadida de que alguma coisa de estranho e novo apagara a sua estrela.

Resolveu desaparecer, fazendo testamento em favor da filha. Uns acreditaram que ela se tivesse lançado ao pântano, porque viram-na dirigir-se para lá, com a sombra da trágica resolução no rosto. Outros, contudo, disseram que, filha dos rios, fora vista descendo o Arauca de canoa. Repentinamente envelhecida, as faces cavadas e em torno dos olhos grandes olheiras de insônia, ela levava, impressa no rosto e no olhar, a calma trágica das determinações supremas.

Aparecendo menos que Santos Luzardo, nem por isso a sua presença deixa de ser acusada em todos os episódios e na ação mesma do romance, onde não só a natureza era bárbara, mas também o próprio homem. Ela era o maior exemplo, não obstante Luzardo, representante da civilização, acabasse sofrendo também o impacto da savana selvagem.

Outras figuras sāo tratadas ainda tão realisticamente quanto essas duas. Figuras menores sem dúvida, como as de Ño Pernalete, de Mujiquita, ou de 
Mr. Danger, norte-americano que se instalara na região e dela gostara porque era bárbara como a sua alma, terra boa para conquistar, segundo os seus cálculos, habitada por gente de raça inferior, porque não tinha cabelos claros e olhos azuis. Ele é bem o tipo da personagem "imperial" a que se refere Sanchez, incorporado ao romance hispano-americano. Encarna o chamado "gringo" que aparece na planície e na selva venezuelana: o gringo mau, abusivo, hipócrita, luxurioso, corruptor, que se aproveita do vício do Barquero e até tenta roubar-lhe a filha, já não falando dos negócios ilícitos que fazia, sócio que chegara a ser de Doña Barbara.

O gringo, é certo, também existe e Gallegos mesmo pode fixá-lo em outras páginas, em outos livros.

Note-se a propósito de Doña Barbara, que o romance finaliza com estas palavras repassadas de confiança e promessa: "Planura venezuelana! Propícia para o esforço como o foi para a façanha, terra de horizontes abertos onde uma raça boa ama, sofre e espera!..."

Não podia haver melhor introdução que esta para o autor de Canaíma e Cantaclaro, dois romances que já se constituem em cantos de louvor à natureza e ao homem, ambos unidos inseparavalmente.

O poeta parece sobrepujar o romancista, como se pode observar logo na primeira página de Canaíma, para muitos a obra mais bem acabada do escritor, principalmente em matéria de estilo. É verdade que o analista de paixões ainda sobrevive aqui, mas a inspiração central do livro está mais nas paisagens, nos quadros de jungle que margeia o Orinoco, do que nos episódios.

Contudo, ainda é possível dizer, como se disse, que a hora de Canaíma é a do índio e sua selva. A figura do herói é a de um deus que seduz $e$ aniquila, uma espécie de Ulisses da selva. Também surge, ao lado de Canaíma, Marcos Vargas, um recém-chegado ou um reingressado, como Santos Luzardo, como Pajarote, como o mesmo Gallegos, que nunca saiu, que esteve sempre de volta à terra bendita cujo simples contato era suficiente para provocar o nascimento de muita coisa.

Ainda subsiste a presença de antigos caudilhos locais, os Ardavines, outros deuses iguais a Canaíma, ao lado de Cholo Parima e Juanifacia, a quem se entrega José Francisco Ardavin, como para ressaltar o mistério da paisagem.

Almas diversas, as suas mudanças se produzem livremente, sem vontade expressa do autor, entregues sempre à decisão da terra, do humus onipotente.

Em Cantaclaro, é a savana que se estende espaçosa desde os pés da cordilheira andina e acompanha em silêncio o curso pausado dos grandes rios solitários, que deslizam até o Orinoco, saltam para o outro lado deste e, em tristes planícies semeadas de rochas duvidosas, definham e se entregam à selva. 
E quem fala em savana, fala logo em cavalo, e copla, comenta o autor. A copla errante que todos os caminhos ouviram passar, companheira do caminhante solitário vergastado por vários sóis nas costas. A que expressa bem os sentimentos campesinos todos sabem de onde provém: de Cantaclaro.

E assim Cantaclaro encarna a copla, o "coplero", a savana, o cavalo, dentro dos aspectos regionais magistralmente fixados pelo romancista ou antes pelo poeta, através das mais fortes metáforas.

Mas a obra de Gallegos continua e ainda não se aludiu a Pobre Negro, outro romance importante, onde aparece um negro de estatura descomunal, mãos atadas nas costas, coberto de sangue, arrastado e espancado por entre a multidão. Mas é sem dúvida a natureza que domina tudo e sob o seu império as criaturas não passam de reflexos e simples comentário.

É o que sucede com José Miguel e Juan Coromoto, personagens do livro, não inventadas, mas antes extraídas da terra, sujeitas à vontade onímoda do meio, a exemplo do que se dá com o próprio autor.

Eis a razão por que se tem dito que o romance venezuelano traduz mais do que outro qualquer da América o meio em que se desenvolvem os seus dramas.

Já no Equador, se no começo, com a publicação de Cumanda, de Juan León Mera, em 1879, ainda era possível falar em natureza, em selva e paisagem, ao lado da reivindicaçāo indígena e do nativismo, com a exaltação de uma raça e uma região. o homem passou a figurar em primeiro plano, como se nota nos romances de Jorge Icaza, seja em Huasipungo, em Cholos, ou En las calles e Huimipamushkas.

Icaza não vê somente o homem, mas também as coletividades e a importância de Huasipungo nasce da intensidade dos fatos ali denunciados: o crioulo rico e o estrangeiro imperialista explorando o indígena nos limites de seu "huasipungo", onde ele nasceu e cresceu, atado sempre aos interesses e a ganância dos amos despóticos que chegam a obrigá-lo a retirar-se dessa pequena área concedida por falsa compaixão de proprietários, na maioria constituídos de brancos arrivistas obscuros ou mestiços sórdidos, "cholada" sem consciência, como diz o autor, ou ainda de curas paroquianos que entram em confabulação com os demais, em prejuízo dos "runas", sempre desamparados.

O índio defende o seu "huasipungo" matando sem piedade e até com crueldade. O seu triunfo, porém, é sempre passageiro, pois ao tenente político derrotado sucede o piquete de tropa vingador, que tem de defender a civilização e, em nome dela, acertar a pontaria sobre quem ousara rebelar-se.

Trata-se no livro de construir uma estrada, para cujo plano contribuiu o nobre don Alfonso Pereira, e então o autor pinta com realismo espantoso a vida do peão e a forma rmpia de seu aproveitamento e utilização pelo branco, 
especialmente nos casos dos "huasipungos", servidores domésticos, ou melhor índios domesticados.

O branco é o senhor, mas um tipo de senhor mesquinho que conserva todlas as anulações da dignidade sacrificada até o seu triunfo.

O que se observa, em suma, é mais a luta dos instintos do que da vontade, a ignorância não deixando margem para nenhum conceito de justiça.

Por sua vez, o proprietário não conserva o prestígio do nome, do avoengo, da nobreza, como antes. Em geral, é um crioulo, mestiço ou até indígena, que soube fazer fortuna, bem ou mal, e, ao chegar a dono de fazenda, julga natural a exploração de uma das riquezas postas em sua mão, o índio. $O$ mesmo se dá com o delegado, o cura, o armazeneiro, o alcaide. Todos exploram o índio, havendo uma gradação de despotismos distribuídos entre esses diversos agentes da tirania enraizada na terra e que as vezes chega a ser perturbada, pela ação supostamente libertadora e que recebe uma infinidade de matizes, desde a generosa do político, do sacerdorte digno, até a mendaz do rábula ou do advogado de má-fé, cujo filão se encontra na desesperação dos atribulados índios, concitados muitas vezes à rebeldia e ao sacrifício, sem nenhum resultado.

Assim, é inegável o sentido da reivindicação humana, de apelo à justiça que se desprende do romance de Icaza como de todo romance equatoriano moderno, de caráter social.

Esse aspecto é, pois, muito visível em Huasipungo, como é também o da linguagem, a sua forma dialetal, a emprestar maior significação a esse documento doloroso da vida primitiva levada ainda hoje pelo índio no Equador.

$O$ índio concentra a atenção do escritor sob vários prismas de sua vida miserável. En las calles, outro romance seu, o tema gira em torno de uma represa construída, cuja existência privava de água a comunidade indígena vizinha. Dos protestos e reclamaçōes feitas por alguns representantes desta decorre arrepiadora matança de índios. Em Cholos, o assunto se desenvolve ao redor de um cacique abusivo e cruel e de um "cholo" vítima de seus complexos de mestiçagem indígena e branca. A tarefa do "cholo" ou do mestiço é sempre desmoralizada.

O autor pinta, afinal, o índio como classe distinta da do branco. Mais do que duas raças constituem duas classes sociais, de modo que esse estado de coisas reinante no Equador provoca em sua obra uma espécie de ódio profético que nada tem a ver com o indianismo idílico de um romântico, como foi Juan León Mera.

Mas há ainda outro país onde o conflito entre índios e brancos, ou seja entre estrangeiros e nativos, adquire importância primordial, que é a Guatemala. 
Dela, entre outros, é que provém Miguel Angel Asturias, romancistas de nome internacional, já traduzido para vários idiomas, detentor do Prêmio Nobel de 1967.

El Señor Presidente, seu grande romance é tido como uma das obrasprimas da literatura contemporânea, além de refletir a atmosfera geral dominante na Guatemala, atua sobre um fundo de realidade transfigurada em feitiçaria e mágicas metamorfoses, para o qual contribui a fantasmagoria das culturas maias, de que $o$ autor se mostra bom conhecedor, ao lado da paisagem, dos elementos não dominados da natureza. Assim, a tradição da raça indígena e a popular espanhola transplantadas para ali, criam atmosfera especial e inconfundível que é a que transparece no romance.

$O$ romancista se afasta da tendência de apresentar o drama do esforço humano em função da natureza, isto é, do ser desamparado ante a potência indomável das selvas e das grandes planuras, como ocorre em Rivera e Gallegos, que souberam imprimir marca de fatalidade aos elementos.

Em Asturias a participação das forças naturais ainda subsiste, pois o homem ainda não dominou a natureza na América, como se sabe, mas as suas incidências assentam mais nos problemas sociais, como se vê em El Serior Presidente, onde se trava a luta de homens contra a força cega e maligna encarnada em outro homem - o ditador que tudo domina, que dispōe em suas mãos da vida de todos os habitantes de uma pequena pátria centro-americana.

Esse ditador, embora de estipe indígena. acabou se convertendo em ídolo dos brancos e a sua crônica foi calcada na do governo de Estrada-Cabrera, personagem sinistro que ficou gravado na memória do povo guatemalteco.

A narrativa introduz o leitor num mundo que, conquanto barroco e absurdo, não deixa de ser menos realista e lógico. O seu estilo logo chama a atenção pelo emprego de assombrosas metáforas, mas o que se impõe mais é o seu profundo mergulho na zona do tradicional-mágico, com o emprego de uma técnica surrealista dos melhores efeitos.

As personagens cruzam a história como restos de um mundo desaparecido e, todavia, com um rosto atual e reconhecivel, como notou um dos críticos do livro. Porque sāo homens encontrados a cada passo, gravam-se de maneira indelével na memória.

Desde o começo alucinante do capítulo intitulado "Portal del Señor", onde é cometido um crime, entre mendigos monstruosos, "sem outro laço comum que a miséria", até a morte quase irreal de "Cara de Angel", favorito do herói, que se casa com a filha do general Canales, cuja perdição tivera o encargo de tramar, são inúmeras as vidas que desfilam, sujeitas ao arbitrio e à crueldade de um homem. 
Os acontecimentos, esses, parecem, dar-se durante a noite, como já se observou. A intriga é tecida com precisão enlouquecedora e tudo gira como se não houvesse sossego para nada. E como alguma coisa de monstruoso está sempre prestes a suceder, a qualquer instante, o ar fica carregado de obscuras premonições, para gerar uma expectativa de tensão insuportável.

Um crítico francês viu o livro como uma espécie de Pátio dos Milagres, de extravagante monumento asteca, feito com carne e polpa de miséria humana, reconhecendo haver poucos livros como este tão carregado de sofrimento e onde a vida esteja pintada com tanto horror.

É certo que, ao lado disso, há nele uma aura poética impalpável, mas profunda, dentro de seu tom alegórico intrínseco, sem nada de deliberado e que é fruto espontâneo dessa inqualificável conjunção da natureza e suas personagens representativas do panorama e da tradição, da sabedoria e da ignorância populares, do folclore, da estética e da liturgia, segundo anota Sanchez com propriedade.

O poeta surge constantemente e tudo parece dominado por um olhar profundo que vai até o âmago dos fatos. A plasticidade sobressai e a conexão metafórica é de tal qualidade que uma poetisa como Gabriela Mistral não titubeou em afirmar estar a obra escrita com a facilidade da respiração e da circulação do sangue pelo corpo. A famosa língua conversacional pela qual Unamuno clamava, cansado de nossas pobres e pretensiosas retóricas, estava presente ali, de forma que ele jamais suspeitou.

Com efeito, em Asturias o idioma atinge o grau de esplendor ignorado até ontem na América. Suas essências mais secretas e deslumbrantes acham-se expressas. E o que é importante - como já foi notado - essa riqueza nada tem do tropicalismo sobre o qual tanto se disse e escreveu, para confundir muitas vezes legítima riqueza com rebuscamento, a exemplo do que se verifica às vezes em Rivera. Aqui, há a mais caudalosa claridade, envolta no equilíbrio mais absoluto, isto é, a expansão convulsiva é sempre dominada pela austeridade, não existindo aquele amontoado de palavras que esconde, sempre, uma incapacidade de pensamento correto.

Acentue-se ainda que esse fenômeno já se patenteava num romance anterior de Asturias, intitulado Hombres de maíz, cujo estilo surge sempre preso ao simbolismo transcendental da existência: "No pasto havia uma mula, sobre a mula havia um homem e no homem havia um morto..."; "O céu ia se cevando de estrelas..."

Neste livro já o leitor se defronta com o mundo primordial dos campesianos maias, a vida oscilando entre os dois movimentos opostos: o milho como produto de lucro, segundo entendem os estrangeiros e os homens da cidade, e o milho como culto e necessidade, segundo as velhas usanças. 
Mas não seria lícito encerrar este ensaio sem fazer referência a outro romance de Asturias: El Papa Verde.

Quem recebeu este apelido foi o ianque Geo Maker Thompson que desembarcou, aos trinta e cinco anos, no porto de uma pequena república da América Central. Renunciando às suas piratarias pelo mar, decidiu ele estabelecer-se como plantador de banana. Desde o seu primeiro entendimento com Ginger Kind, representante de poderosa empresa do ramo, começam a surgir os problemas debatidos no romance.

Kind entendia que os norte-americanos não eram colonialistas, que eles deviam civilizar as populaçōes indígenas através de uma política de tutela: a da parte mais capaz.

Geo respondia que não acreditava nas tutelas civilizadoras: "Os homens são submetidos pela força ou são deixados em paz."

O drama descrito não se circunscreve assim em apenas aos chefes de empresa a aos nativos que defendem as suas liberdades, mas também a longo conflito entre representantes das duas formas do imperialismo ianque.

Para Geo, o drama social ainda será acrescido de uma tragédia íntima. Casando com uma indígena, a jovem e bela Mayari, esta vem a se arrepender quando vê entre ambos cavado um abismo: "Os de tua raça, Geo, estão sempre acordados. Mas nós não. Noite e dia, sonhamos." Vestida de noiva, em núpcias místicas com o rio Motagua, ela acaba se atirando em suas águas. Geo então casa com doña Flora, mãe de Mayari, que morre dando à luz uma criança, Aurélia. Anos mais tarde, esta se deixa seduzir pelo maior inimigo de Geo, que lhe fizera cometer um assassinato inútil. Abandonando Aurélia no momento em que ela ia ser mãe, o sedutor denuncia publicamente os delitos e crimes da "Tropical Platanera" dirigida por Geo. E este que ia triunfar em Chicago estava ameaçado de terminar os seus dias recolhido à vida privada.

Após longa crise social, porém, ele acabará tirando a sua desforra e isso em virtude de dois filantropos americanos terem legado imensa fortuna a sete indigenas com o fito de manter independente a sociedade que tinham constituído. Mas os herdeiros se desentendem e Geo interfere para agravar as rixas entre eles, afirmando que na América Central o único método eficaz é o da "linha curva". Por outro lado, vêm em seu auxílio as manobras de uma companhia rival que provocou um incidente de fronteira entre duas pequenas repúblicas. Evitada a guerra, os Estados Unidos garantem a execução da sentença de arbitragem e Geo Maker Thompson é eleito presidente do gigantesco consórcio frutícula, depois de assegurar para si a maioria das ações.

Esse o entrecho do livro, referto de diálogos apaixonados, de humildes lamentações de oprimidos, de tentativas de rebelião, de brutalidades policiais, de debates de feitiçaria, etc. 
Todos esses elementos, na verdade, estão fundidos para compor um vasto afresco.

Romancista, testemunha apaixonado de sua época e dos problemas de seu país, Asturias encarna admiravelmente o papel do escritor hispano-americano, sempre combativo e nunca conformista, desde o tempo do romantismo, quando já lutava pela justiça política, para lutar hoje pela justiça social.

\section{RESUMO}

Análise da narrativa hispano-americana em seu aspecto de constante testemunho combativo e anticonformista da injustiça social, entre três enfoques nacionais: o Peru de Ciro Alegria com sua problemática agrária e rural e o de Rômulo Gallegos com o vigoroso retrato da lei de violência imperante na planície; o Equador de Mera e Icaza com suas reivindicações indigenistas e exaltantes do nativismo, em meio a "gradação de despotismos" dos agentes da tirania; a Guatemala de Miguel Angel Asturias autor de $O$ senhor presidente e de $O$ papa verde, vasto mural de tentativas de rebelião, brutalidade policial, debates sobre anexação pacífica ou militar, cenas de feitiçaria e humildes lamentações.

\section{RESUMEN}

Análisis de la narrativa hispanoamericana em su aspecto de constante testimonio combativo y anticonformista de la injusticia social, en tres enfoques nacionales: el Perú de Ciro Alegria con su problemática agraria y rural y el de Rômulo Gallegos con el vigoroso retrato de la ley de violencia imperante en la llanura; el Ecuador de Mera e Icaba con sus reivindicaciones indigenistas y exaltantes del nativismo, en medio a la "gradación de despotismos" de los agentes de la tiranía; la Guatemala de Miguel Angel, Asturias autor de El señor presidente y de El papa verde, vasto mural de tentativas de rebelión, brutalidad policial, debates sobre anexación pacífica o militar, escenas de hechicería y humildes lamentaciones. 


\section{REFERÊNCIAS BIBLIOGRÁFICAS}

ALEGRIA, Ciro. El mundo es ancho y ajeno. Santiago : Zig-Zag, 1941. . Los perros hambrientos. Santiago : Zig-Zag, 1939. . La serpiente de oro. Santiago : Ed. Nascimento, 1935.

ANGEL ASTURIAS, Miguel. Hombres de maíz. Buenos Aires : Losada, 1948. . El papa verde. Buenos Aires : Losada, 1953. . El señor presidente. Buenos Aires : Losada, 1948.

GALLEGOS, R. Obras completas; novelas y cuentos. La Habana : Lex, 1949.

ICAZA, Jorge. Cholos. Quito : Impr. Nacional, 1935. . En las calles. Quito : Impr. Nacional, 1934. . Huasipungo. Quito : Impr. Nacional, 1934. . Huirapamushkas. Quito: Casa de Cultura, 1948.

LEON MERA, Juan. Cumandá; o Un drama entre selvagens. 3. ed. Guayaquil : Ed. Telégrafo, 1932. 